\title{
Current status and challenges in drug discovery against the globally important zoonotic cryptosporidiosis
}

\author{
Guan Zhu ${ }^{1 *}$, Jigang Yin ${ }^{1}$ and Gregory D. Cuny ${ }^{2}$
}

\begin{abstract}
The zoonotic cryptosporidiosis is globally distributed, one of the major diarrheal diseases in humans and animals. Cryptosporidium oocysts are also one of the major environmental concerns, making it a pathogen that fits well into the One Health concept. Despite its importance, fully effective drugs are not yet available. Anti-cryptosporidial drug discovery has historically faced many unusual challenges attributed to unique parasite biology and technical burdens. While significant progresses have been made recently, anti-cryptosporidial drug discovery still faces a major obstacle: identification of systemic drugs that can be absorbed by patients experiencing watery diarrhea and effectively pass through electron-dense (ED) band at the parasite-host cell interface to act on the epicellular parasite. There may be a need to develop an in vitro assay to effectively screen hits/leads for their capability to cross ED band. In the meantime, non-systemic drugs with strong mucoadhesive properties for extended gastrointestinal exposure may represent another direction in developing anti-cryptosporidial therapeutics. For developing both systemic and non-systemic drugs, a non-ruminant animal model exhibiting diarrheal symptoms suitable for routine evaluation of drug absorption and anti-cryptosporidial efficacy may be very helpful.
\end{abstract}

Keywords: Cryptosporidium, Cryptosporidiosis, Drug discovery, Watery diarrhea, Electron-dense band, Drug delivery

\section{The zoonotic Cryptosporidium as an important One Health pathogen}

\section{Significance of cryptosporidiosis in human and animal} health

The enteric Cryptosporidium is a globally distributed, water-borne and food-borne diarrheal-causing parasite (Tzipori and Widmer 2000; Checkley et al. 2015). The major symptom of cryptosporidiosis is watery diarrhea that may range from mild to severe or deadly in humans and animals. Currently, there are $\sim 40$ recognized Cryptosporidium species or genotypes (Feng et al. 2018). Humans are mainly infected by the zoonotic C. parvum

\footnotetext{
* Correspondence: zhuguan@jlu.edu.cn

${ }^{1}$ Key Laboratory of Zoonosis Research, Ministry of Education; Institute of Zoonosis; and College of Veterinary Medicine, Jilin University, Changchun, China

Full list of author information is available at the end of the article
}

and anthropogenic C. hominis. Patients with weakened or compromised immunity may be infected by other species (e.g., C. canis, C. felis, C. meleagridis and C. xiaoi) (O'Connor et al. 2011; Adamu et al. 2014; Ryan et al. 2014; Pumipuntu and Piratae 2018). It is also one of the top diarrheal pathogens afflicting children in developing countries with significant negative impact on mortality and growth (Kotloff et al. 2013), resulting in an estimated 4.2 million disability adjusted life years (DALY) lost in children under 5 years old (Khalil et al. 2018). One particular concern is the long-term effects in children, involving growth stunting and cognitive deficits even after the recovery of cryptosporidiosis (Kotloff et al. 2013; Khalil et al. 2018).

Cryptosporidiosis is also a significant health problem in wild and domesticated animals. In farm animals, Cryptosporidium is responsible for the severe to deadly

(c) The Author(s). 2021 Open Access This article is licensed under a Creative Commons Attribution 4.0 International License, which permits use, sharing, adaptation, distribution and reproduction in any medium or format, as long as you give appropriate credit to the original author(s) and the source, provide a link to the Creative Commons licence, and indicate if changes were made. The images or other third party material in this article are included in the article's Creative Commons licence, unless indicated otherwise in a credit line to the material. If material is not included in the article's Creative Commons licence and your intended use is not permitted by statutory regulation or exceeds the permitted use, you will need to obtain permission directly from the copyright holder. To view a copy of this licence, visit http://creativecommons.org/licenses/by/4.0/ The Creative Commons Public Domain Dedication waiver (http://creativecommons.org/publicdomain/zero/1.0/) applies to the data made available in this article, unless otherwise stated in a credit line to the data. 
neonatal diarrhea syndrome of calves and other young ruminants, resulting in considerable direct and indirect economic losses (de Graaf et al. 1999; Olson et al. 2004). Cryptosporidiosis also produces long-term negative effects in animals, including lowering weight gains and production performance in cattle and sheep (Jacobson et al. 2016; Innes et al. 2020; Shaw et al. 2020). For example, beef calves might lose an average of $34 \mathrm{~kg}$ at 6 months of age if they had experienced cryptosporidiosis as neonates in comparison to those with no clinical signs of infection (Shaw et al. 2020).

\section{Cryptosporidium as a One Health model pathogen}

Oocysts are environmental stage of the parasite responsible for transmission between humans and/or animals. Oocysts contain a wall structure that is highly resistant to chemicals including disinfectants, while the 4 sporozoites within an oocyst wall are reasonably resistant to temperature fluctuation and desiccation, probably related to the presence of stress protectant trehalose $(\mathrm{Yu}$ et al. 2010). For these reasons, cryptosporidium oocysts are a significant environmental contaminant, responsible for numerous water-borne outbreaks of cryptosporidiosis around the world (Corso et al. 2003; Chyzheuskaya et al. 2017; Ridderstedt et al. 2018). Long-surviving oocysts may be carried to different places around the world in water and soil to interact with humans and animals, and adapted to new environments and hosts, which complicate the evolution of epidemiology and population structures of cryptosporidiosis (Feng et al. 2018). Therefore, Cryptosporidium may serve as one of the model One Health pathogens that impact human, animal and environmental health at regional and global levels (Fig. 1) (Ryan et al. 2016; Innes et al. 2020).

\section{Unique intracellular lifestyle of Cryptosporidium}

Cryptosporidium is transmitted via fecal-oral route, and has a unique epi-cytoplasmic lifestyle (i.e., intracellular, but extra-cytoplasmic) (Prystajecky et al. 2014). When humans or animals ingest oocysts, sporozoites are released from oocysts to invade intestinal epithelial cells, starting its intracellular development. In humans and other mammals, ileum is the major infection site for intestinal cryptosporidium species (Leitch and $\mathrm{He}$ 2012; Abdou et al. 2013).

Parasite mainly infects intestinal epithelial cells, where it is separated from the host cell cytosol by an electrondense (ED) band and associated structures, but embraced by a host cell-derived parasitophorous vacuole membrane (PVM) (Fig. 2) (Elliott and Clark 2000). This epi-cytoplasmic location makes Cryptosporidium different from other apicomplexans that reside within the host cell cytosol (e.g., Eimeria, Toxoplasma and Plasmodium).

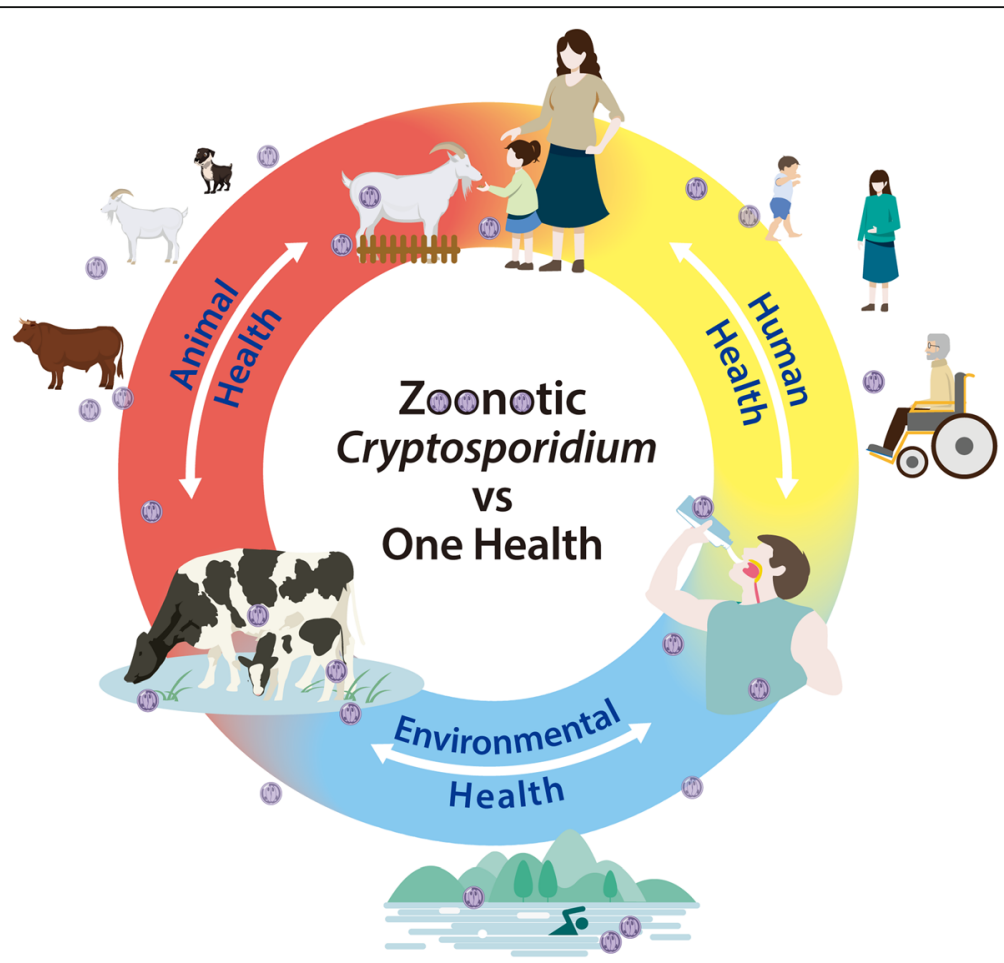

Fig. 1 Interactions and impact of Cryptosporidium on human, animal and environmental health under the One Health concept. The stressresistant oocysts play a central role in transmission of cryptosporidial infections between and among humans and animals via direct contact and/ or contamination of environment. Credit to Lin Xia and Wenjuan Wang for illustration 


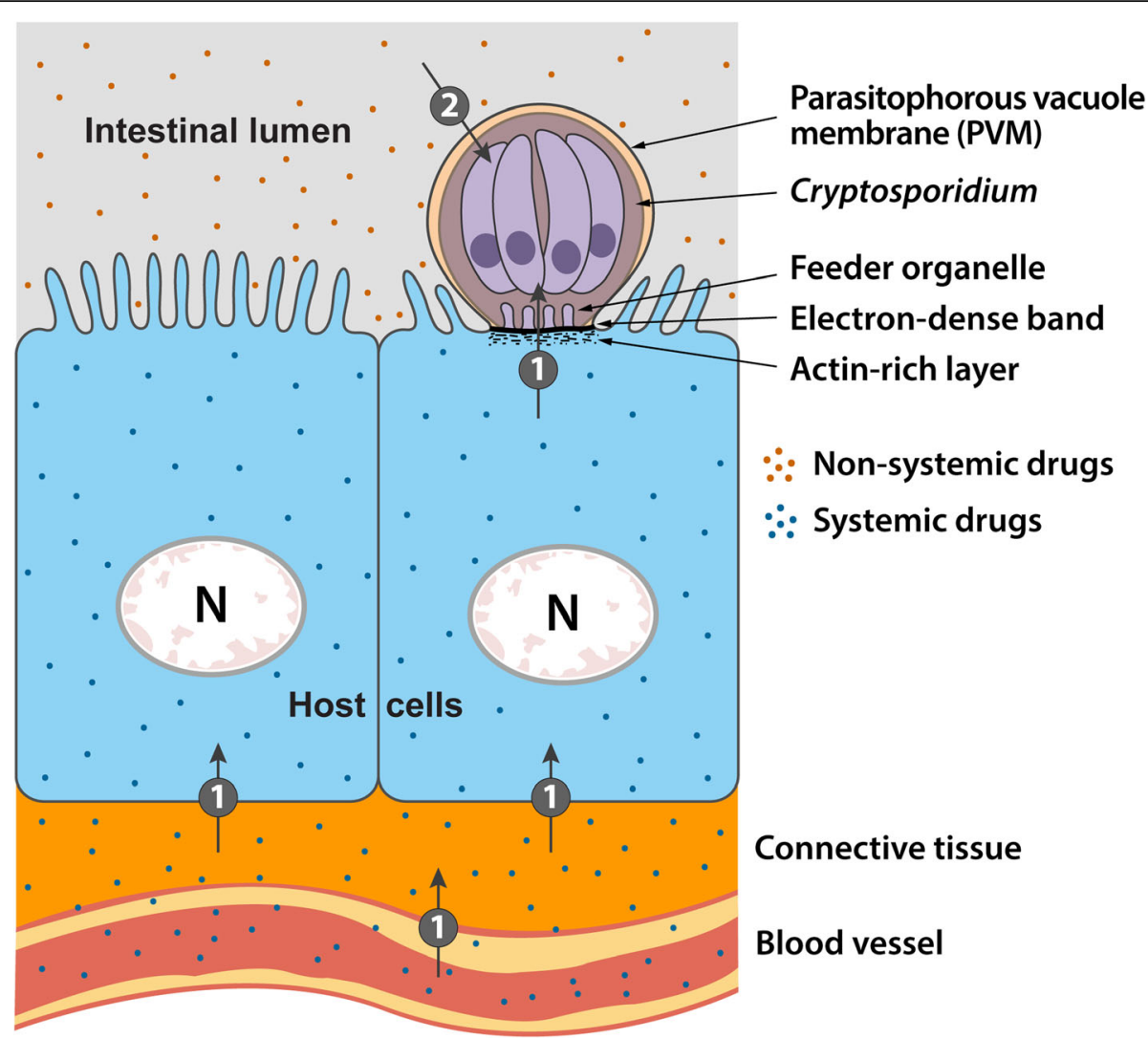

Fig. 2 Illustration of drug delivery routes for systemic and non-systemic drugs to an intracellular Cryptosporidium meront that is separated from host epithelial cell cytosol by an electron-dense (ED) band, but embraced by a host cell-derived parasitophorous vacuole membrane (PVM) facing the intestinal lumen. Systemic drugs need to cross through the selective ED band and feeder organelle (route 1), while luminal non-systemic drugs may directly act on parasite through PVM (route 2). A regular 2D culture system is unable to evaluate systemic drug route since the basal surface of host cells is attached to a nonporous plastic surface. Credit to Lin Xia and Wenjuan Wang for illustration

\section{Current status of anti-cryptosporidial drug discovery}

\section{Limited treatment options}

Despite its medical and veterinary importance, current options to treat cryptosporidiosis in humans and animals are limited. Only nitazoxanide is approved by the Food and Drug Administration (FDA) in the United States to treat cryptosporidiosis in immune-competent individuals, but not for immuno-compromised individuals, such as AIDS patients (Chappell and Okhuysen 2002; White Jr. 2003; Jenkins 2004; Smith and Corcoran 2004; Fox and Saravolatz 2005). However, nitazoxanide is not fully effective (Fox and Saravolatz 2005), and has an illdefined mechanism of action. There is also no FDAapproved drugs to treat cryptosporidiosis in animals. In some countries, halofuginone lactate (Halocur) is approved for veterinary use in calves and lambs, which displays some anti-cryptosporidial efficacy, but again it's not fully effective in eliminating oocyst production (Klein 2008; Trotz-Williams et al. 2011; Petermann et al. 2014).
Recently discovered anti-cryptosporidial leads and targets An increasing effort over the past two decades has led to the discovery of several lead compounds with defined targets and anti-cryptosporidial efficacies at lower nanomolar level in vitro and low $\mathrm{mg} / \mathrm{kg} / \mathrm{d}$ doses in mouse models. A few of them have also been evaluated in calves. These leads include "compound 5" on lysyl-tRNA synthetase (KRS) (Baragana et al. 2019), BRD7929 on phenylalanyl-tRNA synthetase (PheRS) (Vinayak et al. 2020), inhibitors of bumped-kinase (Arnold et al. 2017; Lee et al. 2018; Huang et al. 2019), "compound 1294" on calcium-dependent protein kinase (CDPK) (CastellanosGonzalez et al. 2013), P131 on inosine-5' -mono-phosphate dehydrogenase (IMPDH), (Gorla et al. 2014), KDU731 on phosphatidylinositol-4-OH kinase (PI (4) K) (Manjunatha et al. 2017), triacsin C on acyl-CoA synthetase (ACS) (Guo et al. 2014), vorinostat on histone deacetylase (HDAC) (Guo et al. 2018), and gossypol on lactate dehydrogenase (LDH) (Zhang et al. 2015; Li et al. 2019). However, they are mostly in various preclinical and lead optimization stages. Even if one or more of 
these leads (or analogs) are developed into therapeutics in the future, more drug options are still needed to diversify drug targets and for overcoming potential drug resistance.

More recently, a randomized, double-blind, placebocontrolled study on the efficacy of clofazimine for treating cryptosporidiosis in HIV-infected patients was reported. However, the "findings do not support the efficacy of clofazimine for the treatment of cryptosporidiosis in a severely immunocompromised HIV population" (Iroh Tam et al. 2020). This further exemplifies the difficulties in developing anti-cryptosporidial drugs.

\section{Historical challenges and progresses in anti- cryptosporidial drug discovery}

Anti-cryptosporidial drug discovery faces additional challenges compared to other apicomplexans. Limiting factors are present at virtually all stages of drug development pipeline from basic research to preclinical investigations (Fig. 3). This section will briefly discuss the historical challenges and progress related to anticryptosporidial drug discovery and development.

\section{Limited availability of parasite materials}

A major limiting factor impeding research and drug discovery in this particular field is the difficulties in obtaining large number of pure parasite materials for experiments. The zoonotic species C. parvum is the most commonly used species in research, for which oocysts can be obtained at a reasonable scale from bovine neonatal calves (up to billions of oocysts), or in limited amounts in some immunodeficient mice (up to millions of oocysts). Oocysts can be isolated from calf feces by gradient centrifugation procedures and further cleaned using chlorine to achieve high purity. Free sporozoites can be obtained by in vitro excystation (Arrowood and Sterling 1987; Arrowood and Donaldson 1996; Arrowood 2020). Therefore, oocysts and sporozoites are the only 2 stages for which highly pure materials can be obtained for experimental use. For C. hominis, only a gnotobiotic piglet model is available for maintaining and propagating certain parasite isolates in specialized facilities (Lee et al. 2018, 2019).

\section{Lack of continuous in vitro cultivation platform for routine use}

In vitro culture protocols of $C$. parvum have been established for decades. Parasite oocysts can undergo excystation to release sporozoites that invade host cells and develop for 2-3 days under in vitro condition. The in vitro growth is mostly limited to asexual stages (i.e., merogony), and up to the formation of macro- and micro-gametes that are unable to fertilize to form zygotes and viable oocysts (Tandel et al. 2019). In vitro culture can provide less synchronized meronts and merozoites in host cells for microscopic and molecular

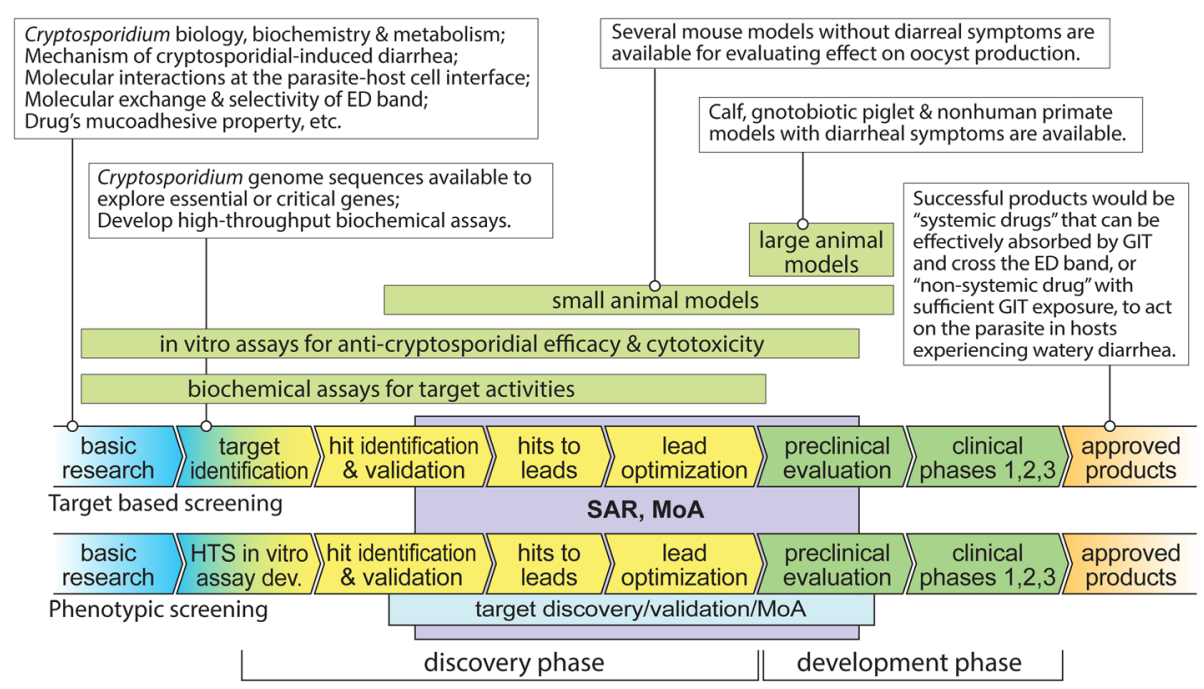

Fig. 3 Illustration and brief annotation of drug discovery pipeline, major assays and models in target-based and phenotypic screening approaches. Yellow and green boxes indicate discovery and developmental phases. In both approaches, structure-activity relationship (SAR) and mode of action $(\mathrm{MOA})$ analysis may be started shortly after hits are identified and extended to later stages. In the phenotypic screening approach, discovery of target by the identified hit may be needed for determining MoA. Biochemical assays and in vitro assays may be developed in the basic research phase and used throughout the discovery phase, and extended into the preclinical phase. Small animal models are used in discovery and preclinical phases, while large animal models are used in preclinical phase. For drug discovery against cryptosporidiosis, it's critical to discover efficacious systemic drugs that can be effectively absorbed by human or animal patients and cross electron-dense (ED) band at the parasite-host cell interface, or non-systemic drugs that have sufficient gastrointestinal tract (GIT) exposure for acting on the epicellular parasite (as illustrated in Fig. 2) 
experiments, but is unable to propagate parasite for providing unlimited materials. The inability to continuously grow parasite in vitro has been a significant obstacle for both cryptosporidium and coccidia (such as Eimeria species) (Muller and Hemphill 2013). For comparison, Toxoplasma and Plasmodium parasites have a merozoite stage that can be continuously cultured in fibroblasts or erythrocytes in vitro (Muller and Hemphill 2013; Szabo and Finney 2017; Bermudez et al. 2018; Duffy and Avery 2018).

More recently, complete life cycle development of $C$. parvum was obtained using a stem-cell-derived platform, which represents a progress milestone in cryptosporidium research (Wilke et al. 2019). Another notable development is the continuous 3D cultivation of Cryptosporidium in hollow fiber bioreactors (Morada et al. 2016; Yarlett et al. 2020), and a few bioengineered intestinal models based on silk-protein scaffold, colon explants or lung/small intestine organoids cultured with parasites over weeks (Baydoun et al. 2017; DeCicco RePass et al. 2017; Heo et al. 2018). A more comprehensive review on these organoids and bioengineered intestinal models was reported by Gunasekera et al. (2020). Nonetheless, these models and platforms are not yet optimized for routine production of oocysts, and remain technically challenging for regular laboratory use. However, they raise hope for further optimization and adaptation.

\section{Absence of conventional drug targets}

At a basic biology level, cryptosporidium lacks many drug targets present in other apicomplexans because of a highly streamlined metabolism and absence of de novo nutrient synthetic pathways (e.g., amino acids, nucleotides and fatty acids), or targets that are highly divergent (e.g., DHFR) (Abrahamsen et al. 2004; Xu et al. 2004; Zhu 2007; Rider Jr. and Zhu 2010). The difficult genehunting game was concluded in 2004 after the whole genome sequences of several Cryptosporidium species (Abrahamsen et al. 2004; Xu et al. 2004; Rider Jr. and Zhu 2010; Ifeonu et al. 2016), providing opportunities for investigators to intellectually explore various essential or critical proteins and pathways as potential drug targets (see Current status of anti-cryptosporidial drug discovery section above for examples on recently discovered leads and targets). Although not every explored target will lead to a successful clinically validated drug, the more we explore, the higher probability that one or more drugs operating via different action modes could be eventually developed.

\section{Available now but still tricky genetic manipulation}

At the genetic level, there used to be a lack of tools for ultimate drug target validation. This obstacle is partially resolved by the successful development of CRIPR/Cas9based genome-editing tools in C. parvum and C. tyzzeri (Vinayak et al. 2015; Sateriale et al. 2019, 2020). It is now possible to conduct gene knockout to evaluate the essentialness or importance of a gene in cryptosporidium, albeit the tool may not be easily adapted for use by routine laboratories. Conditional gene knockout strategies are also under development for studying essential genes and validating drug targets (Choudhary et al. 2020). The mouse-specific species C. tyzzeri is evolutionarily more closely related to $C$. parvum and $C$. hominis than other species that infecting mammals (Sateriale et al. 2019), and more convenient for laboratory manipulation. Therefore, C. tyzzeri may serve as a great genetic model for studying the core biological questions, and for acquiring preliminary and proof-of-concept data, prior to conducting experiments using $C$. parvum and $C$. hominis.

There are also notable reports of 2 Cryptosporidium gene-silencing strategies: one uses morpholino antisense oligonucleotides with success in knockdown parasite lactate dehydrogenase $(L D H)$ gene expression (Witola et al. 2017; Zhang et al. 2018), and the other employs recombinant human Argonaute protein (hAgo2) preassembled with single-stranded RNA (ssRNA) of targeted genes (Castellanos-Gonzalez et al. 2016, 2019).

\section{Development of in vitro phenotypic screening platforms} At the phenotypic screening level, in vitro culture of $C$. parvum in 96- or 384-well plates can be readily achieved to a satisfactory uniformity between wells by an experienced researcher. The earlier challenge for highthroughput screening or evaluating drug efficacy against cryptosporidial growth with traditional methods are either time-consuming (microscopic counting of the parasite) or have narrow linear dynamic range (e.g., ELISA or chemiluminescent assays using anti-cryptosporidial antibodies).

This obstacle has been cleared after the development and optimization of 2 platforms based on high-content imaging analysis (Bessoff et al. 2013), a luciferase assay using transgenic cryptosporidium strains (Manjunatha et al. 2017), and a qRT-PCR-based approach (Zhang and Zhu 2015, 2020). Among them, qRT-PCR assay omits a nucleic acid isolation step by directly using diluted cell lysates as templates, making it more easily adapted for use by other laboratories that lack a plate imaging facility and are unable to develop or acquire transgenic parasite strains.

\section{Availability and limitations of animal models}

In evaluating drug efficacy in animals, there is a lack of small animal models mimicking acute and chronic cryptosporidiosis with watery diarrhea, the hallmark 
clinical symptom of cryptosporidiosis. Mouse neonates and several immunodeficient breeds are the most commonly used small animal models that are unable to produce diarrheal symptoms, but sufficient to assess the effect of a drug on oocyst production (CastellanosGonzalez et al. 2013; Guo et al. 2014, 2018; Arnold et al. 2017; Manjunatha et al. 2017; Lee et al. 2018; Baragana et al. 2019; Huang et al. 2019).

Bovine calves and gnotobiotic piglets produce watery diarrhea with experimental cryptosporidial infections, and have been developed into reproducible large animal models for evaluating anti-cryptosporidial drug efficacy (Schaefer et al. 2016; Manjunatha et al. 2017; Lee et al. 2018, 2019; Riggs and Schaefer 2020). As one of the native hosts of zoonotic C. parvum, drug absorption and efficacy data from bovine calves are directly relevant to treat calf cryptosporidiosis. However, it's difficult to test multiple calves in a reasonable timeframe, and data from calves may be less applicable to humans due to fundamental differences in digestive anatomy and physiology (Toutain et al. 2010; Hatton et al. 2015; Ziegler et al. 2016).

On the other hand, piglets have the advantage for infection of both C. parvum and C. hominis (Lee et al. 2018 , 2019). In comparison with ruminants, drug absorption and efficacy data obtained from piglets may be more applicable to humans due to the similarity between human and porcine digestive systems (Theodos et al. 1998; Manjunatha et al. 2017; Lee et al. 2018). In addition to calves and piglets, a nonhuman primate model using pigtailed macaques (Macaca nemestrina) was reported in the early 1990's (Miller et al. 1990, 1991). This reproducible experimental model showed clinical symptoms as humans, and can be useful in the final stage of preclinical investigations.

\section{Current challenges in developing therapeutics and potential solutions}

As discussed above, cryptosporidial research community has confronted the unusual challenges in anticryptosporidial drug discovery and is making significant progress. Phenotypic screening and target-based approaches have resulted in the discovery of a number of leads displaying excellent anti-cryptosporidial efficacy in vivo. Some anti-cryptosporidial drug discovery and development programs are ready for (or close to) clinical investigation, while more may be in the stage of lead optimization. However, the field is still facing a final challenge in developing a clinically successful drug to treat patients experiencing severe watery diarrhea.

ED band as an extra barrier for delivery of systemic drugs Most of the drug discovery efforts focus on systemic drugs, but the "epicellular" (i.e., intracellular but extra- cytoplasmic) lifestyle of parasite creates an extra burden for systemic drugs to cross ED band and reach parasite (Fig. 2). Molecular compositions and functions of parasite-host cell interface are still poorly understood, but one can assume that ED band is the major pathway for parasite to acquire nutrients from host cell cytoplasm (Leitch and He 2012). Therefore, ED band is expected to be highly "selective" in allowing molecules to pass through from host cells. This may explain that a significant number of excellent anti-cryptosporidial hits/leads identified by in vitro screening showed unsatisfactory efficacy in vivo.

A successful systemic drug must be able to pass through ED band. Data derived from mouse models can be indicative, in which the efficacy of a systemic drug would show strong correlation with pharmacokinetic parameters in plasma, rather than with luminal or fecal drug concentrations (Castellanos-Gonzalez et al. 2013; Guo et al. 2014, 2018; Arnold et al. 2017; Manjunatha et al. 2017; Lee et al. 2018; Baragana et al. 2019; Huang et al. 2019). Animal experiments are costly and timeconsuming, although acute infection mouse models may be used to test more compounds with reduced costs and time (Guo et al. 2018).

Therefore, an in vitro assay that can conveniently evaluate the permeability of ED band for small molecules will be very helpful for prioritizing identify hits/ leads for subsequent evaluation in animals. Current 2D or $3 \mathrm{D}$ cultivation platforms can be applied to in vitro evaluation of pharmacokinetic and pharmacodynamic properties of potential lead compounds prior to animal studies (Morada et al. 2016; Yarlett et al. 2020), but none of them is able to evaluate systemic drug route since drugs are directly exposed to parasite. However, it is technically achievable to grow a layer of tightly connected host cells, in which Cryptosporidium resides on top of host cells on one side of the layer while drugs can be applied to the other side to achieve the host-cell-tothe-parasite delivery route.

\section{Absorption as an important factor in drug discovery against the diarrheal-causing cryptosporidiosis}

Another obstacle is related to absorption of systemic drugs, as they may be "flushed out" quickly from GIT (gastrointestinal tract), giving insufficient time for absorption by hosts experiencing severe watery diarrhea. Combination of an anti-cryptosporidial drug with an anti-diarrheal medicine may improve efficacy, although anti-diarrheal medicines have a limited effect to ease cryptosporidial-induced diarrheal symptoms (Checkley et al. 2015).

Novel pharmacological modifications and formulations may be employed to increase drug absorption in individuals experiencing severe diarrhea, such as by enhancing 
drug's mucoadhesion property (Pridgen et al. 2015; Purohit et al. 2018), and/or by exploring the enterohepatic recycling pathway to increase gastrointestinal exposure and bioavailability (Xia et al. 2012; Dai et al. 2015).

Evaluation of drug absorption and anti-cryptosporidial efficacy in animals is also a challenge, because these properties cannot be fully assessed in current mouse models that exhibit no diarrheal symptoms, and routine evaluation of a large number of drugs in neonatal calf and gnotobiotic piglet models are impractical. Therefore, the development of more convenient piglet models (vs. gnotobiotic piglets) can be very helpful to overcome the bottleneck in preclinical evaluation of anticryptosporidial drugs.

\section{Non-systemic drugs as an alternative strategy}

Another approach is to develop "non-systemic" drugs to more directly act on the epicellular parasite in GIT. It is known that some compounds cannot be well absorbed, or unable to effectively pass ED band to act on parasite, but gastrointestinal exposure is critical to their anticryptosporidial activity (e.g., paromomycin and some bumped kinase inhibitors) (Arnold et al. 2017).

More recently, a glycolipopeptide occidiofungin featured by poor absorbability and GIT retainment was found to be highly efficacious on C. parvum in vitro with limited cytotoxicity (Ma et al. 2020). These observations suggest that non-systemic drugs may be an effective alternative to develop systemic drugs. However, nonsystemic drugs would still face the same challenge of being flushed out by diarrhea, which may be resolved by increasing the mucoadhesive property and/or in combination of anti-diarrheal medicines to increase their retention in host GIT.

\section{Conclusions}

Cryptosporidiosis is an important zoonotic disease for which fully effective treatments are unavailable. The epicellular (intracellular, but extra-cytoplasmic) parasitic lifestyle makes the diarrheal pathogen cryptosporidium different from other enteric coccidia that reside within host cell cytosol, and creates unique challenges in developing therapeutics. Systemic drugs need to be not only absorbed rapidly by GIT of humans and animals that typically experiencing severe watery diarrhea, but also to effectively pass through the selective ED band to act on parasite. It would be helpful to develop an in vitro assay to effectively screen hits/leads for their permeability over ED band.

Non-systemic drugs may be an effective alternative direction, as they only need to cross PVM to act on parasite. For non-systemic drugs, the ability to cross PVM is not a major concern for hits/leads that already show satisfactory efficacy in vitro. Challenge is their retainment in GIT of individuals experiencing diarrhea. For both systemic and non-systemic drugs, improving mucoadhesive property by formulation or chemical modification would be helpful to absorption for systemic drugs and to retainment for non-systemic drugs, to achieve significant efficacy in humans.

\section{Acknowledgements}

The authors were supported in part by grants from the National Key Research and Development Program of China 2017 YFC1601206 (J.Y.) and the National Institutes of Health, USA R01Al125362 (G.D.C.).

Authors' contributions

All authors have read and approved the final version of the manuscript.

\section{Declarations}

\section{Competing interests}

The authors declare that they have no competing interests.

\section{Author details}

${ }^{1}$ Key Laboratory of Zoonosis Research, Ministry of Education; Institute of Zoonosis; and College of Veterinary Medicine, Jilin University, Changchun, China. ${ }^{2}$ Department of Pharmacological \& Pharmaceutical Sciences, College of Pharmacy, University of Houston, Houston, TX, USA.

Received: 20 December 2020 Accepted: 28 January 2021 Published online: 23 April 2021

\section{References}

Abdou, A.G., N.M. Harba, A.F. Afifi, and N.F. Elnaidany. 2013. Assessment of Cryptosporidium parvum infection in immunocompetent and immunocompromised mice and its role in triggering intestinal dysplasia. International Journal of Infectious Diseases 17 (8): e593-e600. https://doi.org/1 0.1016/j.ijid.2012.11.023.

Abrahamsen, M.S., T.J. Templeton, S. Enomoto, J.E. Abrahante, G. Zhu, C.A. Lancto, M. Deng, C. Liu, G. Widmer, S. Tzipori, G.A. Buck, P. Xu, A.T. Bankier, P.H. Dear, B.A. Konfortov, H.F. Spriggs, L. lyer, V. Anantharaman, L. Aravind, and V. Kapur. 2004. Complete genome sequence of the apicomplexan, Cryptosporidium parvum. Science 304 (5669): 441-445. https://doi.org/10.1126/science.1094786.

Adamu, H., B. Petros, G. Zhang, H. Kassa, S. Amer, J. Ye, Y. Feng, and L. Xiao. 2014. Distribution and clinical manifestations of Cryptosporidium species and subtypes in HIV/AIDS patients in Ethiopia. PLoS Neglected Tropical Diseases 8 (4): e2831. https://doi.org/10.1371/journal.pntd.0002831.

Arnold, S.L.M., R. Choi, M.A. Hulverson, D.A. Schaefer, S. Vinayak, R.S.R. Vidadala, M. C. Mccloskey, G.R. Whitman, W. Huang, L.K. Barrett, et al. 2017. Necessity of bumped kinase inhibitor gastrointestinal exposure in treating Cryptosporidium infection. The Journal of Infectious Diseases 216 (1): 55-63. https://doi.org/10.1093/infdis/jix247.

Arrowood, M.J. 2020. Cryptosporidium Oocyst purification using discontinuous gradient centrifugation. Methods in Molecular Biology 2052: 43-59. https://doi. org/10.1007/978-1-4939-9748-0_4.

Arrowood, M.J., and K. Donaldson. 1996. Improved purification methods for calfderived Cryptosporidium parvum oocysts using discontinuous sucrose and cesium chloride gradients. The Journal of Eukaryotic Microbiology 43 (5): 895. https://doi.org/10.1111/j.1550-7408.1996.tb05015.x.

Arrowood, M.J., and C.R. Sterling. 1987. Isolation of Cryptosporidium oocysts and sporozoites using discontinuous sucrose and isopycnic Percoll gradients. The Journal of Parasitology 73 (2): 314-319. https://doi.org/10.2307/3282084.

Baragana, B., B. Forte, R. Choi, S. Nakazawa Hewitt, J.A. Bueren-Calabuig, J.P. Pisco, C. Peet, D.M. Dranow, D.A. Robinson, C. Jansen, et al. 2019. Lysyl-tRNA synthetase as a drug target in malaria and cryptosporidiosis. Proceedings of the National Academy of Sciences of the United States of America 116 (14): 7015-7020. https://doi.org/10.1073/pnas.1814685116.

Baydoun, M., S.B. Vanneste, C. Creusy, K. Guyot, N. Gantois, M. Chabe, B. Delaire, A. Mouray, A. Baydoun, G. Forzy, V. Chieux, P. Gosset, V. Senez, E. Viscogliosi, J. Follet, and G. Certad. 2017. Three-dimensional (3D) culture of adult murine colon as an in vitro model of cryptosporidiosis: Proof of concept. Scientific Reports 7 (1): 17288. https://doi.org/10.1038/s41598-017-17304-2. 
Bermudez, M., D.A. Moreno-Perez, G. Arevalo-Pinzon, H. Curtidor, and M.A. Patarroyo. 2018. Plasmodium vivax in vitro continuous culture: The spoke in the wheel. Malaria Journal 17 (1): 301. https://doi.org/10.1186/s12936-018-24 56-5.

Bessoff, K., A. Sateriale, K.K. Lee, and C.D. Huston. 2013. Drug repurposing screen reveals FDA-approved inhibitors of human HMG-CoA reductase and isoprenoid synthesis that block Cryptosporidium parvum growth. Antimicrobial Agents and Chemotherapy 57 (4): 1804-1814. https://doi.org/10.1128/AAC.024 60-12.

Castellanos-Gonzalez, A., G. Martinez-Traverso, K. Fishbeck, S. Nava, and A.C. White Jr. 2019. Systematic gene silencing identified Cryptosporidium nucleoside diphosphate kinase and other molecules as targets for suppression of parasite proliferation in human intestinal cells. Scientific Reports 9 (1): 12153. https://doi.org/10.1038/s41598-019-48544-z

Castellanos-Gonzalez, A., N. Perry, S. Nava, and A.C. White Jr. 2016. Preassembled single-stranded RNA-Argonaute complexes: A novel method to silence genes in Cryptosporidium. The Journal of Infectious Diseases 213 (8): 1307-1314. https://doi.org/10.1093/infdis/jiv588.

Castellanos-Gonzalez, A., A.C. White Jr., K.K. Ojo, R.S. Vidadala, Z. Zhang, M.C. Reid, A.M. Fox, K.R. Keyloun, K. Rivas, A. Irani, et al. 2013. A novel calciumdependent protein kinase inhibitor as a lead compound for treating cryptosporidiosis. The Journal of Infectious Diseases 208 (8): 1342-1348. https://doi.org/10.1093/infdis/jit327.

Chappell, C.L., and P.C. Okhuysen. 2002. Cryptosporidiosis. Current Opinion in Infectious Diseases 15 (5): 523-527. https://doi.org/10.1097/00001432-20021 0000-00012.

Checkley, W., A.C. White Jr., D. Jaganath, M.J. Arrowood, R.M. Chalmers, X.M. Chen, R. Fayer, J.K. Griffiths, R.L. Guerrant, L. Hedstrom, C.D. Huston, K.L. Kotloff, G. Kang, J.R. Mead, M. Miller, W.A. Petri Jr., J.W. Priest, D.S. Roos, B. Striepen, R.C.A. Thompson, H.D. Ward, W.A. van Voorhis, L. Xiao, G. Zhu, and E.R. Houpt. 2015. A review of the global burden, novel diagnostics, therapeutics, and vaccine targets for cryptosporidium. The Lancet Infectious Diseases 15 (1): 85-94. https://doi.org/10.1016/S1473-3099(14)70772-8.

Choudhary, H.H., M.G. Nava, B.E. Gartlan, S. Rose, and S. Vinayak. 2020. A conditional protein degradation system to study essential gene function in Cryptosporidium parvum. mBio 11 (4). https://doi.org/10.1128/mBio.01231-20.

Chyzheuskaya, A., M. Cormican, R. Srivinas, D. O'donovan, M. Prendergast, C. O'donoghue, and D. Morris. 2017. Economic assessment of waterborne outbreak of cryptosporidiosis. Emerging Infectious Diseases 23 (10): 1650-1656. https://doi.org/10.3201/eid2310.152037

Corso, P.S., M.H. Kramer, K.A. Blair, D.G. Addiss, J.P. Davis, and A.C. Haddix. 2003. Cost of illness in the 1993 waterborne Cryptosporidium outbreak, Milwaukee, Wisconsin. Emerging Infectious Diseases 9 (4): 426-431. https://doi.org/10.32 01/eid0904.020417

Dai, P., L. Zhu, F. Luo, L. Lu, Q. Li, L. Wang, Y. Wang, X. Wang, M. Hu, and Z. Liu. 2015. Triple recycling processes impact systemic and local bioavailability of orally administered flavonoids. The AAPS Journal 17 (3): 723-736. https://doi. org/10.1208/s12248-015-9732-x.

De Graaf, D.C., E. Vanopdenbosch, L.M. Ortega-Mora, H. Abbassi, and J.E. Peeters. 1999. A review of the importance of cryptosporidiosis in farm animals. International Journal for Parasitology 29 (8): 1269-1287. https://doi.org/10.101 6/S0020-7519(99)00076-4

Decicco Repass, M.A., Y. Chen, Y. Lin, W. Zhou, D.L. Kaplan, and H.D. Ward. 2017. Novel bioengineered three-dimensional human intestinal model for longterm infection of Cryptosporidium parvum. Infection and Immunity 85 (3). https://doi.org/10.1128/IAl.00731-16.

Duffy, S., and V.M. Avery. 2018. Routine in vitro culture of Plasmodium falciparum: Experimental consequences? Trends in Parasitology 34 (7): 564-575. https:// doi.org/10.1016/j.pt.2018.04.005

Elliott, D.A., and D.P. Clark. 2000. Cryptosporidium parvum induces host cell actin accumulation at the host-parasite interface. Infection and Immunity 68 (4): 2315-2322. https://doi.org/10.1128/IAl.68.4.2315-2322.2000.

Feng, Y., U.M. Ryan, and L. Xiao. 2018. Genetic diversity and population structure of Cryptosporidium. Trends in Parasitology 34 (11): 997-1011. https://doi.org/1 0.1016/j.pt.2018.07.009.

Fox, L.M., and L.D. Saravolatz. 2005. Nitazoxanide: a new thiazolide antiparasitic agent. Clinical Infectious Diseases 40 (8): 1173-1180. https:/doi.org/10.1086/428839.

Gorla, S.K., N.N. Mcnair, G. Yang, S. Gao, M. Hu, V.R. Jala, B. Haribabu, B. Striepen, G.D. Cuny, J.R. Mead, et al. 2014. Validation of IMP dehydrogenase inhibitors in a mouse model of cryptosporidiosis. Antimicrobial Agents and Chemotherapy 58 (3): 1603-1614. https://doi.org/10.1128/AAC.02075-13.
Gunasekera, S., A. Zahedi, M. O'dea, B. King, P. Monis, B. Thierry, J.M. Carr, and U. Ryan. 2020. Organoids and bioengineered intestinal models: Potential solutions to the Cryptosporidium culturing dilemma. Microorganisms 8 (5). https://doi.org/10.3390/microorganisms8050715.

Guo, F., H. Zhang, J.M. Fritzler, S.D. Rider Jr., L. Xiang, N.N. Mcnair, J.R. Mead, and G. Zhu. 2014. Amelioration of Cryptosporidium parvum infection in vitro and in vivo by targeting parasite fatty acyl-coenzyme A synthetases. The Journal of Infectious Diseases 209 (8): 1279-1287. https://doi.org/10.1093/infdis/jit645.

Guo, F., H. Zhang, N.N. Mcnair, J.R. Mead, and G. Zhu. 2018. The existing drug vorinostat as a new lead against cryptosporidiosis by targeting the parasite histone deacetylases. The Journal of Infectious Diseases 217 (7): 1110-1117. https://doi.org/10.1093/infdis/jix689.

Hatton, G.B., V. Yadav, A.W. Basit, and H.A. Merchant. 2015. Animal farm: Considerations in animal gastrointestinal physiology and relevance to drug delivery in humans. Journal of Pharmaceutical Sciences 104 (9): 2747-2776. https://doi.org/10.1002/jps.24365.

Heo, I., D. Dutta, D.A. Schaefer, N. lakobachvili, B. Artegiani, N. Sachs, K.E. Boonekamp, G. Bowden, A.P.A. Hendrickx, R.J.L. Willems, P.J. Peters, M.W. Riggs, R. O'Connor, and H. Clevers. 2018. Modelling Cryptosporidium infection in human small intestinal and lung organoids. Nature Microbiology 3 (7): 814 823. https://doi.org/10.1038/s41564-018-0177-8.

Huang, W., M.A. Hulverson, R. Choi, S.L.M. Arnold, Z. Zhang, M.C. Mccloskey, G.R. Whitman, R.C. Hackman, K.L. Rivas, L.K. Barrett, et al. 2019. Development of 5Aminopyrazole-4-carboxamide-based bumped-kinase inhibitors for cryptosporidiosis therapy. Journal of Medicinal Chemistry 62 (6): 3135-3146. https://doi.org/10.1021/acs.jmedchem.9b00069.

Ifeonu, O.O., M.C. Chibucos, J. Orvis, Q. Su, K. Elwin, F. Guo, H. Zhang, L. Xiao, M. Sun, R.M. Chalmers, et al. 2016. Annotated draft genome sequences of three species of Cryptosporidium: Cryptosporidium meleagridis isolate UKMEL1, C. baileyi isolate TAMU-09Q1 and C. hominis isolates TU502_2012 and UKH1. FEMS Pathogens and Disease 74 (7). https://doi.org/10.1093/femspd/ftw080.

Innes, E.A., R.M. Chalmers, B. Wells, and M.C. Pawlowic. 2020. A one health approach to tackle cryptosporidiosis. Trends in Parasitology 36 (3): 290-303. https://doi.org/10.1016/j.pt.2019.12.016.

Iroh Tam, P.Y., S.L.M. Arnold, L.K. Barrett, C.R. Chen, T.M. Conrad, E. Douglas, M.A. Gordon, D. Hebert, M. Henrion, D. Hermann, et al. 2020. Clofazimine for treatment of cryptosporidiosis in HIV-infected adults (CRYPTOFAZ): An experimental medicine, randomized, double-blind, placebo-controlled phase 2a trial. Clinical Infectious Diseases. https://doi.org/10.1093/cid/ciaa421.

Jacobson, C., A. Williams, R. Yang, U. Ryan, I. Carmichael, A.J. Campbell, and G.E. Gardner. 2016. Greater intensity and frequency of Cryptosporidium and Giardia oocyst shedding beyond the neonatal period is associated with reductions in growth, carcase weight and dressing efficiency in sheep. Veterinary Parasitology 228: 42-51. https://doi.org/10.1016/j.vetpar.2016.08.003.

Jenkins, M.C. 2004. Present and future control of cryptosporidiosis in humans and animals. Expert Review of Vaccines 3 (6): 669-671. https://doi.org/10.1586/14 760584.3.6.669.

Khalil, I.A., C. Troeger, P.C. Rao, B.F. Blacker, A. Brown, T.G. Brewer, D.V. Colombara, E.L. De Hostos, C. Engmann, R.L. Guerrant, et al. 2018. Morbidity, mortality, and long-term consequences associated with diarrhoea from Cryptosporidium infection in children younger than 5 years: A meta-analyses study. The Lancet Global Health 6 (7): e758-e768. https://doi.org/10.1016/ S2214-109X(18)30283-3.

Klein, P. 2008. Preventive and therapeutic efficacy of halofuginone-lactate against Cryptosporidium parvum in spontaneously infected calves: A centralised, randomised, double-blind, placebo-controlled study. Veterinary Journal 177 (3): 429-431. https://doi.org/10.1016/j.tvjl.2007.05.007.

Kotloff, K.L., J.P. Nataro, W.C. Blackwelder, D. Nasrin, T.H. Farag, S. Panchalingam, Y. Wu, S.O. Sow, D. Sur, R.F. Breiman, A.S.G. Faruque, A.K.M. Zaidi, D. Saha, P.L. Alonso, B. Tamboura, D. Sanogo, U. Onwuchekwa, B. Manna, T. Ramamurthy, S. Kanungo, J.B. Ochieng, R. Omore, J.O. Oundo, A. Hossain, S.K. Das, S. Ahmed, S. Qureshi, F. Quadri, R. A. Adegbola, M. Antonio, MJ. Hossain, A. Akinsola, I. Mandomando, T. Nhampossa, S. Acácio, K. Biswas, C.E. O'Reilly, E.D. Mintz, L.Y. Berkeley, K. Muhsen, H. Sommerfelt, R.M. Robins-Browne, and M.M. Levine. 2013. Burden and aetiology of diarrhoeal disease in infants and young children in developing countries (the Global Enteric Multicenter Study, GEMS): A prospective, case-control study. Lancet 382 (9888): 209-222. https:// doi.org/10.1016/S0140-6736(13)60844-2.

Lee, S., G. Beamer, and S. Tzipori. 2019. The piglet acute diarrhea model for evaluating efficacy of treatment and control of cryptosporidiosis. Human vaccines \& Immunotherapeutics 15 (6): 1445-1452. https://doi.org/10.1080/21 645515.2018 .1498436 
Lee, S., M. Ginese, G. Beamer, H.R. Danz, D.J. Girouard, S.P. Chapman-Bonofiglio, M. Lee, M.A. Hulverson, R. Choi, G.R. Whitman, K.K. Ojo, S.L.M. Arnold, W.C. van Voorhis, and S. Tzipori. 2018. Therapeutic efficacy of bumped kinase inhibitor 1369 in a pig model of acute diarrhea caused by Cryptosporidium hominis. Antimicrobial Agents and Chemotherapy 62 (7): e00147-e00118. https://doi.org/10.1128/AAC.00147-18.

Leitch, G.J., and Q. He. 2012. Cryptosporidiosis-an overview. Journal of Biomedical Research 25 (1): 1-16. https://doi.org/10.1016/S1674-8301(11)60001-8.

Li, K., S.M. Nader, X. Zhang, B.C. Ray, C.Y. Kim, A. Das, and W.H. Witola. 2019. Novel lactate dehydrogenase inhibitors with in vivo efficacy against Cryptosporidium parvum. PLoS Pathogens 15 (7): e1 007953. https://doi.org/1 0.1371/journal.ppat.1007953.

Ma, J., F. Guo, Z. Jin, M. Geng, M. Ju, A. Ravichandran, R. Orugunty, L. Smith, G. Zhu, and H. Zhang. 2020. Novel antiparasitic activity of the antifungal lead occidiofungin. Antimicrobial Agents and Chemotherapy 64 (8). https://doi. org/10.1128/AAC.00244-20.

Manjunatha, U.H., S. Vinayak, J.A. Zambriski, A.T. Chao, T. Sy, C.G. Noble, G.M.C. Bonamy, R.R. Kondreddi, B. Zou, P. Gedeck, C.F. Brooks, G.T. Herbert, A. Sateriale, J. Tandel, S. Noh, S.B. Lakshminarayana, S.H. Lim, L.B. Goodman, C. Bodenreider, G. Feng, L. Zhang, F. Blasco, J. Wagner, F.J. Leong, B. Striepen, and T.T. Diagana. 2017. A Cryptosporidium PI (4) K inhibitor is a drug candidate for cryptosporidiosis. Nature 546 (7658): 376-380. https://doi.org/1 0.1038 /nature22337.

Miller, R.A., M.A. Bronsdon, and W.R. Morton. 1990. Experimental cryptosporidiosis in a primate model. The Journal of Infectious Diseases 161 (2): 312-315. https://doi.org/10.1093/infdis/161.2.312.

Miller, R.A., M.A. Bronsdon, and W.R. Morton. 1991. Failure of breast-feeding to prevent Cryptosporidium infection in a primate model. The Journal of Infectious Diseases 164 (4): 826-827. https://doi.org/10.1093/infdis/164.4.826.

Morada, M., S. Lee, L. Gunther-Cummins, L.M. Weiss, G. Widmer, S. Tzipori, and N. Yarlett. 2016. Continuous culture of Cryptosporidium parvum using hollow fiber technology. International Journal for Parasitology 46 (1): 21-29. https:// doi.org/10.1016/j.jpara.2015.07.006

Muller, J., and A. Hemphill. 2013. In vitro culture systems for the study of apicomplexan parasites in farm animals. International Journal for Parasitology 43 (2): 115-124. https://doi.org/10.1016/j.ijpara.2012.08.004

O'Connor, R.M., R. Shaffie, G. Kang, and H.D. Ward. 2011. Cryptosporidiosis in patients with HIV/AIDS. AIDS 25 (5): 549-560. https://doi.org/10.1097/QAD. Ob013e3283437e88

Olson, M.E., R.M. O'handley, B.J. Ralston, T.A. Mcallister, and R.C. Thompson. 2004 Update on Cryptosporidium and Giardia infections in cattle. Trends in Parasitology 20 (4): 185-191. https://doi.org/10.1016/j.pt.2004.01.015.

Petermann, J., C. Paraud, I. Pors, and C. Chartier. 2014. Efficacy of halofuginone lactate against experimental cryptosporidiosis in goat neonates. Veterinary Parasitology 202 (3-4): 326-329. https://doi.org/10.1 016/j.vetpar.2014.02.027.

Pridgen, E.M., F. Alexis, and O.C. Farokhzad. 2015. Polymeric nanoparticle drug delivery technologies for oral delivery applications. Expert Opinion on Drug Delivery 12 (9): 1459-1473. https://doi.org/10.1517/17425247.201 5.1018175.

Prystajecky, N., P.M. Huck, H. Schreier, and J.L. Isaac-Renton. 2014. Assessment of Giardia and Cryptosporidium spp. as a microbial source tracking tool for surface water: Application in a mixed-use watershed. Applied and Environmental Microbiology 80 (8): 2328-2336. https://doi.org/10.1128/AEM.02 037-13.

Pumipuntu, N., and S. Piratae. 2018. Cryptosporidiosis: A zoonotic disease concern. Veterinary World 11 (5): 681-686. https://doi.org/10.14202/vetworld.2 018.681-686.

Purohit, T.J., S.M. Hanning, and Z. Wu. 2018. Advances in rectal drug delivery systems. Pharmaceutical Development and Technology 23 (10): 942-952. https://doi.org/10.1080/10837450.2018.1484766.

Ridderstedt, F., M. Widerstrom, J. Lindh, and M. Lilja. 2018. Sick leave due to diarrhea caused by contamination of drinking water supply with Cryptosporidium hominis in Sweden: a retrospective study. Journal of Water and Health 16 (5): 704-710. https://doi.org/10.2166/wh.2017.311.

Rider, S.D., Jr., and G. Zhu. 2010. Cryptosporidium: Genomic and biochemical features. Experimental Parasitology 124 (1): 2-9. https://doi.org/10.1016/j. exppara.2008.12.014.

Riggs, M.W., and D.A. Schaefer. 2020. Calf clinical model of cryptosporidiosis for efficacy evaluation of therapeutics. Methods in Molecular Biology 2052: 253282. https://doi.org/10.1007/978-1-4939-9748-0_15.
Ryan, U., R. Fayer, and L. Xiao. 2014. Cryptosporidium species in humans and animals: Current understanding and research needs. Parasitology 141 (13): 1667-1685. https://doi.org/10.1017/\$0031182014001085.

Ryan, U., A. Zahedi, and A. Paparini. 2016. Cryptosporidium in humans and animals-a one health approach to prophylaxis. Parasite Immunology 38 (9): 535-547. https://doi.org/10.1111/pim.12350.

Sateriale, A., M. Pawlowic, S. Vinayak, C. Brooks, and B. Striepen. 2020. Genetic manipulation of Cryptosporidium parvum with CRISPR/Cas9. Methods in Molecular Biology 2052: 219-228. https://doi.org/10.1007/978-1-4939-9748$0 \_13$.

Sateriale, A., J. Slapeta, R. Baptista, J.B. Engiles, J.A. Gullicksrud, G.T. Herbert, C.F. Brooks, E.M. Kugler, J.C. Kissinger, C.A. Hunter, et al. 2019. A genetically tractable, natural mouse model of cryptosporidiosis offers insights into host protective immunity. Cell Host \& Microbe 26 (1): 135-146.e135. https://doi. org/10.1016/j.chom.2019.05.006.

Schaefer, D.A., D.P. Betzer, K.D. Smith, Z.G. Millman, H.C. Michalski, S.E. Menchaca, J.A. Zambriski, K.K. Ojo, M.A. Hulverson, S.L. Arnold, et al. 2016. Novel bumped kinase inhibitors are safe and effective therapeutics in the calf clinical model for cryptosporidiosis. The Journal of Infectious Diseases 214 (12): 1856-1864. https://doi.org/10.1093/infdis/jiw488.

Shaw, H.J., E.A. Innes, L.J. Morrison, F. Katzer, and B. Wells. 2020. Long-term production effects of clinical cryptosporidiosis in neonatal calves. International Journal for Parasitology 50 (5): 371-376. https://doi.org/10.1016/j. ijpara.2020.03.002.

Smith, H.V., and G.D. Corcoran. 2004. New drugs and treatment for cryptosporidiosis. Current Opinion in Infectious Diseases 17 (6): 557-564. https://doi.org/10.1097/00001432-200412000-00008.

Szabo, E.K., Finney, C.a.M., 2017. Toxoplasma gondii: One organism, multiple models. Trends in Parasitology 33 (2): 113-127. doi: https://doi.org/10.1016/j. pt.2016.11.007.

Tandel, J., E.D. English, A. Sateriale, J.A. Gullicksrud, D.P. Beiting, M.C. Sullivan, B. Pinkston, and B. Striepen. 2019. Life cycle progression and sexual development of the apicomplexan parasite Cryptosporidium parvum. Nature Microbiology 4 (12): 2226-2236. https://doi.org/10.1038/s41564-019-0539-x.

Theodos, C.M., J.K. Griffiths, J. D'onfro, A. Fairfield, and S. Tzipori. 1998. Efficacy of nitazoxanide against Cryptosporidium parvum in cell culture and in animal models. Antimicrobial Agents and Chemotherapy 42 (8): 1959-1965. https:// doi.org/10.1128/AAC.42.8.1959.

Toutain, P.L., A. Ferran, and A. Bousquet-Melou. 2010. Species differences in pharmacokinetics and pharmacodynamics. Handbook of Experimental Pharmacology 199: 19-48. https://doi.org/10.1007/978-3-642-10324-7_2.

Trotz-Williams, L.A., B.D. Jarvie, A.S. Peregrine, T.F. Duffield, and K.E. Leslie. 2011. Efficacy of halofuginone lactate in the prevention of cryptosporidiosis in dairy calves. The Veterinary Record 168 (19): 509. https://doi.org/10.1136/vr.d14 92.

Tzipori, S., and G. Widmer. 2000. The biology of Cryptosporidium. Contributions to Microbiology 6: 1-32. https://doi.org/10.1159/000060370.

Vinayak, S., R.S. Jumani, P. Miller, M.M. Hasan, B.I. Mcleod, J. Tandel, E.E. Stebbins, J. E. Teixeira, J. Borrel, A. Gonse, et al. 2020. Bicyclic azetidines kill the diarrheal pathogen Cryptosporidium in mice by inhibiting parasite phenylalanyl-tRNA synthetase. Science Translational Medicine 12 (563): e563. https://doi.org/1 0.1126/scitranslmed.aba8412.

Vinayak, S., M.C. Pawlowic, A. Sateriale, C.F. Brooks, C.J. Studstill, Y. Bar-Peled, M.J. Cipriano, and B. Striepen. 2015. Genetic modification of the diarrhoeal pathogen Cryptosporidium parvum. Nature 523 (7561): 477-480. https://doi. org/10.1038/nature 14651

White, A.C., Jr. 2003. Nitazoxanide: An important advance in anti-parasitic therapy. The American Journal of Tropical Medicine and Hygiene 68 (4): 382-383. https://doi.org/10.4269/ajtmh.2003.68.382.

Wilke, G., L.J. Funkhouser-Jones, Y. Wang, S. Ravindran, Q. Wang, W.L. Beatty, M.T. Baldridge, K.L. Vandussen, B. Shen, M.S. Kuhlenschmidt, et al. 2019. A stemcell-derived platform enables complete Cryptosporidium development in vitro and genetic tractability. Cell Host \& Microbe 26 (1): 123-134.e128. https://doi. org/10.1016/j.chom.2019.05.007.

Witola, W.H., X. Zhang, and C.Y. Kim. 2017. Targeted gene knockdown validates the essential role of lactate dehydrogenase in Cryptosporidium panum. International Journal for Parasitology 47 (13): 867-874. https://doi.org/10.1016/j.jpara.2017.05.002.

Xia, B., Q. Zhou, Z. Zheng, L. Ye, M. Hu, and Z. Liu. 2012. A novel local recycling mechanism that enhances enteric bioavailability of flavonoids and prolongs their residence time in the gut. Molecular Pharmaceutics 9 (11): 3246-3258. https://doi.org/10.1021/mp300315d. 
Xu, P., G. Widmer, Y. Wang, L.S. Ozaki, J.M. Alves, M.G. Serrano, D. Puiu, P. Manque, D. Akiyoshi, A.J. Mackey, W.R. Pearson, P.H. Dear, A.T. Bankier, D.L. Peterson, M.S. Abrahamsen, V. Kapur, S. Tzipori, and G.A. Buck. 2004. The genome of Cryptosporidium hominis. Nature 431 (7012): 1107-1112. https://doi.org/10.103 8/nature02977.

Yarlett, N., M. Morada, M. Gobin, W. Van Voorhis, and S. Arnold. 2020. In vitro culture of Cryptosporidium parvum using hollow fiber bioreactor: Applications for simultaneous pharmacokinetic and pharmacodynamic evaluation of test compounds. Methods in Molecular Biology 2052: 335-350. https://doi.org/10.1 007/978-1-4939-9748-0_19.

Yu, Y., H. Zhang, and G. Zhu. 2010. Plant-type trehalose synthetic pathway in Cryptosporidium and some other apicomplexans. PLoS One 5 (9): e12593. https://doi.org/10.1371/journal.pone.0012593.

Zhang, H., F. Guo, and G. Zhu. 2015. Cryptosporidium lactate dehydrogenase is associated with the parasitophorous vacuole membrane and is a potential target for developing therapeutics. PLoS Pathogens 11 (11): e1005250. https:// doi.org/10.1371/journal.ppat.1005250.

Zhang, H., and G. Zhu. 2015. Quantitative RT-PCR assay for high-throughput screening (HTS) of drugs against the growth of Cryptosporidium parvum in vitro. Frontiers in Microbiology 6: e991. https://doi.org/10.3389/fmicb.2015. 00991.

Zhang, H., and G. Zhu. 2020. High-throughput screening of drugs against the growth of Cryptosporidium parvum in vitro by qRT-PCR. Methods in Molecular Biology 2052: 319-334. https://doi.org/10.1007/978-1-4939-9748-0_18.

Zhang, X., C.Y. Kim, T. Worthen, and W.H. Witola. 2018. Morpholino-mediated in vivo silencing of Cryptosporidium parvum lactate dehydrogenase decreases oocyst shedding and infectivity. International Journal for Parasitology 48 (8): 649-656. https://doi.org/10.1016/j.jpara.2018.01.005.

Zhu, G. 2007. Biochemistry. In Cryptosporidium and cryptosporidiosis, ed. R. Fayer and L. Xiao, 57-77. Boca Raton: CRC Press.

Ziegler, A., L. Gonzalez, and A. Blikslager. 2016. Large animal models: The key to translational discovery in digestive disease research. Cellular and Molecular Gastroenterology and Hepatology 2 (6): 716-724. https://doi.org/10.1016/j. jcmgh.2016.09.003.

\section{Publisher's Note}

Springer Nature remains neutral with regard to jurisdictional claims in published maps and institutional affiliations.

Ready to submit your research? Choose BMC and benefit from:

- fast, convenient online submission

- thorough peer review by experienced researchers in your field

- rapid publication on acceptance

- support for research data, including large and complex data types

- gold Open Access which fosters wider collaboration and increased citations

- maximum visibility for your research: over $100 \mathrm{M}$ website views per year

At $\mathrm{BMC}$, research is always in progress.

Learn more biomedcentral.com/submissions 